\title{
Effects of food type and abundance on begging and sharing in Asian small-clawed otters (Aonyx cinereus)
}

\author{
Madison Bowden-Parry ${ }^{\text {Corresp., } 1}$, Erik Postma ${ }^{1}$, Neeltje Boogert ${ }^{1}$ \\ ${ }^{1}$ Department of Biosciences, University of Exeter, Penryn, Cornwall, United Kingdom \\ Corresponding Author: Madison Bowden-Parry \\ Email address: madisonbowdenparry@gmail.com
}

Begging for food, a conspicuous solicitation display, is common in a variety of taxa, and it has received extensive research attention in a parent-offspring context. Both theoretical models and empirical evidence suggest that offspring begging can be an honest signal of hunger or a mediator of competition between siblings. At a behavioural mechanistic level, begging for food can be a form of harassment aimed at persuading those in possession of food to share. Food sharing, defined as the transfer of a defendable food item from one individual to another, can vary considerably between species, age-classes and food type and abundance. We investigated the determinants of begging and food-sharing behaviours in Asian small-clawed otters (Aonyx cinereus), a group-living species that commonly exhibits begging in captivity. We presented two captive otter populations with three food types that varied in exploitation complexity, in three different abundances. We predicted that begging rates would be highest when food was in lowest abundance and hardest to exploit, and that increased begging would lead to increased food sharing. We found that, over time, increased begging rates were indeed correlated with increased food transfers, but neither food type complexity nor abundance affected begging or sharing rates. However, age category was significantly associated with begging and food sharing rates: juvenile otters begged more and shared less than adult otters. The results from this first experimental study on begging and food sharing within the Mustelid family begin to reveal some of the drivers of these behaviours. 
1 Effects of food type and abundance on begging and sharing in Asian 2 small-clawed otters (Aonyx cinereus)

3

4 Madison Bowden-Parry $^{1}$, Erik Postma ${ }^{1}$ and Neeltje J. Boogert ${ }^{1}$

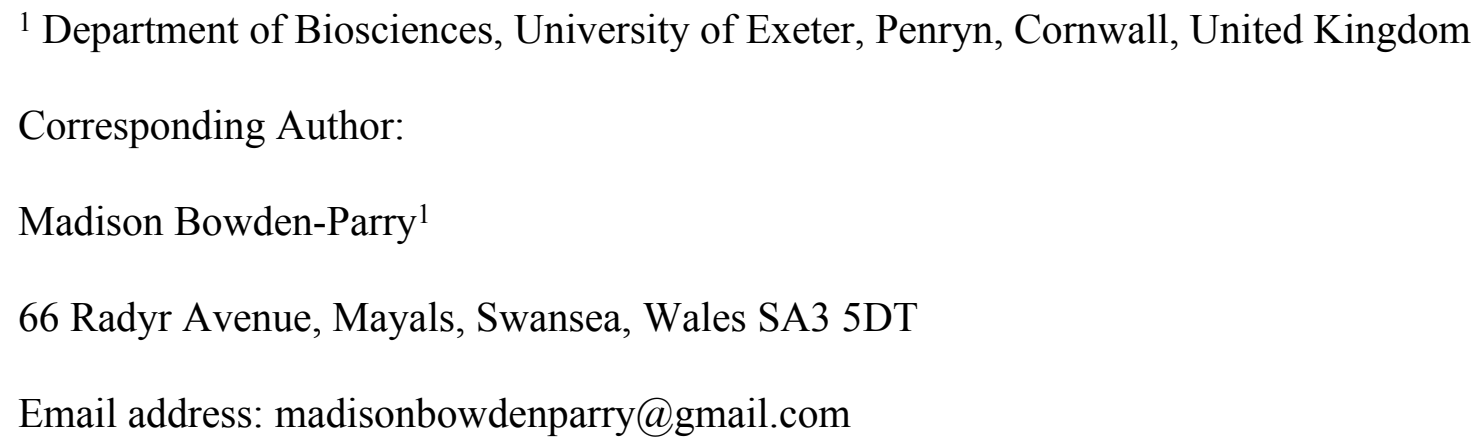




\section{Abstract}

30 Begging for food, a conspicuous solicitation display, is common in a variety of taxa, and it has

31 received extensive research attention in a parent-offspring context. Both theoretical models and

32 empirical evidence suggest that offspring begging can be an honest signal of hunger or a

33 mediator of competition between siblings. At a behavioural mechanistic level, begging for food

34 can be a form of harassment aimed at persuading those in possession of food to share. Food

35 sharing, defined as the transfer of a defendable food item from one individual to another, can

36 vary considerably between species, age-classes and food type and abundance. We investigated

37 the determinants of begging and food-sharing behaviours in Asian small-clawed otters (Aonyx

38 cinereus), a group-living species that commonly exhibits begging in captivity. We presented two

39 captive otter populations with three food types that varied in exploitation complexity, in three

40 different abundances. We predicted that begging rates would be highest when food was in lowest

41 abundance and hardest to exploit, and that increased begging would lead to increased food

42 sharing. We found that, over time, increased begging rates were indeed correlated with increased

43 food transfers, but neither food type complexity nor abundance affected begging or sharing rates.

44 However, age category was significantly associated with begging and food sharing rates:

45 juvenile otters begged more and shared less than adult otters. The results from this first

46 experimental study on begging and food sharing within the Mustelid family begin to reveal some

47 of the drivers of these behaviours. 


\section{Introduction}

50 Begging for food, a conspicuous display that can involve both physical and vocal solicitation

51 behaviours (Kilner and Johnstone 1997; Wright and Leonard 2007), is widespread across taxa

52 (Bayern et al. 2007; Carter and Wilkinson 2013; Gilby 2006; Goodall 1986; Hauser 1992;

53 Hauser and Marler 1993; Silk et al. 2013) and has received extensive research attention in a

54 parent-offspring context (Trivers 1974; Royle et al. 2002). Theoretical models of begging have

55 focussed on the nutritional demands of offspring and food solicitation interactions with their

56 parents (Grafen 1990; Zahavi 1975). These models, and empirical evidence, support two main

57 explanations for begging: an 'honest signal of hunger' (Bowers et al. 2019; Kilner and Johnstone

58 1997; Godfray 1991,1995; Mock and Parker 1997), which is most commonly tested in young

59 birds (e.g., Capodeanu-Nägler et al. 2017; Christe et al. 1996; Karasov and Wright 2002), and

60 competition between siblings for the acquisition of food from parents, known as the 'sibling

61 scramble hypothesis’ (Harper 1986; Stamps et al. 1978; Macnair and Parker 1979; Parker 1985).

62 As begging and the resultant food sharing are typically documented to occur between kin, these

63 interactions can be explained by inclusive fitness benefits (Hamilton 1964).

64 Although food sharing is common between relatives, it also occurs between unrelated

65 conspecifics, mates, adults and non-biological offspring (de Kort et al. 2006; Feistner and

66 McGrew 1989; Jaeggi et al. 2008). Food sharing is commonly observed in nonhuman animals,

67 including primates (de Waal 2000; Jaeggi and Van Schaik 2011; Silk et al. 2013), corvids

68 (termed 'allofeeding', de Kort et al. 2006; Heinrich 1988; Stacey and Koenig 1990; Thiollay

69 1991), leaf-nosed bats (vampire bats: Carter and Wilkinson 2013; Denault and McFarlane 1995;

70 Wilkinson 1984), oceanic dolphins (Fedorowicz et al. 2003; Hoelzel 1991; Wright et al. 2016),

71 rodents (spiny mice: Porter, Moore and White 1981) and big cats (Cooper 1991). It is widely

72 defined as the transfer of a defendable food item from one food-motivated individual to another, 
73 which in many circumstances is an unresisted transfer (de Kort et al. 2006; Feistner and McGrew

74 1989; Hadjichrysanthou and Broom 2012). However, the exact definition of food sharing appears

75 to depend on species and context (Hadjichrysanthou and Broom 2012).

76 While food sharing between kin is easily explained through inclusive fitness benefits, at a

77 mechanistic level food sharing may be motivated by harassment avoidance (Carter and

78 Wilkinson 2013; Gilby 2006; Jones 1984; Stevens and Stephens 2002; Wrangham 1975; Wright

79 and Leonard 2007). The harassment avoidance (or 'sharing-under-pressure') hypothesis states

80 that persistent begging might coerce conspecifics into sharing their food. Similar to the 'tolerated

81 theft' model of food sharing in humans (Blurton Jones 1984, 1987; Isaac 1978), sharing can

82 provide benefits to food owners. By sharing, food owners can reduce further harassment by

83 beggars, and thus gain the benefits of dismissing the recipient and eating the remainder of their

84 food in peace (Jones 1984; de Kort et al. 2006; Stevens and Stephens 2002; Stevens 2004;

85 Wrangham 1975). However, unlike tolerated theft, the harassment avoidance hypothesis in not

86 contingent upon hunger asymmetry (Blurton Jones Jones 1984, 1987; Isaac 1978) and predicts

87 that (1) harassment is costly to the food owner, (2) harassment elicits food sharing and (3) food

88 sharing reduces harassment (Stevens and Stephens 2002). In this study, we tested whether

89 begging and sharing frequencies were correlated within two family groups.

90 Both begging and food sharing frequencies vary considerably between species, age

91 groups and contexts (Boesch et al. 2002; Hadjichrysanthou and Broom 2012). Factors such as

92 food availability and food type may explain some of this variation (Elgar 1986). For example,

93 food availability has been shown to influence offspring begging frequencies in various bird

94 species (Quillfeldt and Masello 2004; Price and Ydenberg 1995; Smith and Montgomerie 1991),

95 with food limitation increasing overall begging activity and intensity (Budden and Wright 2001; 
96 Kilner and Johnstone 1997; Watson and Ritchinson 2018). Food type can also influence begging

97 frequency: increased begging for novel food types has been observed in several primate species,

98 such as chimpanzees (Nishida and Turner 1996), marmosets (Brown et al. 2005), lion tamarins

99 (Price and Fiestner 1993) and cotton-top tamarins (Feistner and Chamove 1986), although this is

100 not always the case (bonobo; Kuroda 1984). Studies of how both food abundance and food type

101 influence begging and food sharing frequencies in non-primate mammals remain rare. Here, we

102 tested whether some of the variation in begging and sharing frequencies may be explained by

103 food abundance and food type in two family groups of otters (de Waal 2000).

104 Food sharing by adults with dependent offspring is common among various primate

105 species (Feistner and Price 1990, 2000; Hiraiwa-Hasegawa 1990; Jaeggi et al. 2008; Nishida and

106 Turner 1996; Rapaport and Ruiz-Miranda 2002; Ruiz-Miranda et al. 1999; Silk 1978; Ueno and

107 Matsuzawa 2004). In some species of Callitrichids (Feistner and Price 1990; 2000; Rapaport and

108 Ruiz-Miranda 2002; Ruiz-Miranda et al. 1999), food transfers mostly involve 'difficult-to-

109 process' foods, are controlled by adults, and peak during weaning. However, in chimpanzees,

110 most food transfers of difficult-to-process foods occur before weaning (Hiraiwa-Hasegawa 1990;

111 Nishida and Turner 1996; Silk 1978). In some cases, such food transfers are begged for and

112 controlled by juveniles rather than adults (Jaeggi et al. 2008; Nishida and Turner 1996; Ueno and

113 Matsuzawa 2004). In orangutans, offspring solicitation is dependent upon foraging skill level,

114 with more competent offspring soliciting fewer food items than dependent offspring (Jaeggi et al.

115 2008). In this study, we tested whether otter age classes differed in their foraging efficiency and

116 begging and sharing frequencies.

117 We studied the gregarious Asian small-clawed otter, the smallest of all 13 extant species

118 within the Mustelid family (Aziz 2018; Foster-Turley 1992; Hussain et al. 2011; Wayre 1978). 
119 This species is a suitable model system to examine drivers of food sharing behaviour, because

120 they form large family romps (ca. 12 individuals), exhibit extreme begging behaviour in

121 captivity (i.e., incessant, loud vocalisations towards zookeepers and each other prior to and

122 during provisioning times) that can be quantified to test for harassment avoidance, and they are

123 abundant in zoos and wildlife centres. Asian small-clawed otters feed on both fish and

124 invertebrates in the wild (Chanin 1985; Mason and Macdonald 1987), are independent foragers

125 at 13 months old (Watt 1991; 1993) and have a very high metabolic rate (Marshall et al. 1988).

126 Some individuals will consume $20-25 \%$ of their body mass in food per day (Costa and Kooyman

127 1982; Kenyon 1969; Morrison et al. 1974), suggesting that the energetic cost of food sharing, as

128 well as begging, might be relatively high in this species.

129 We presented two captive family groups with three food types that varied in the

130 complexity of their prey defences (inferred by exploitation latency) in three different

131 abundances. First, we tested the prediction from the harassment avoidance hypothesis (Stevens

132 and Stephens 2002; Wrangham 1975) that, assuming harassment was costly to food owners,

133 otters would show more food sharing the more begging they received. We also predicted that,

134 given their high metabolic rate and nutritional needs, otters would beg more for food when food

135 abundance was low, and when food was difficult to exploit. However, in these circumstances

136 (i.e., of low food abundance), one might expect less sharing as food owners might be less

137 responsive to the begging of group mates when their own nutritional needs take priority. We also

138 predicted that juveniles would harass (i.e., beg) more and share less than adults, given that

139 juvenile animals typically show less efficient foraging behaviour, and are nutritionally dependent

140 on adults (Bolnick et al. 2003; Capodeanu-Nägler et al. 2017). 
141 Materials \& Methods

142 Ethical statement

143

144 The University of Exeter departmental ethics committee (2018/2334), Newquay Zoo and the

145 Tamar Otter and Wildlife Centre approved all experiments in this study.

\section{Subjects}

147 This study was conducted on two groups of otter, all of which were captive-born and raised. The

148 group kept at the Tamar Otter and Wildlife Centre in Launceston consisted of 12 related subjects

149 including 6 adults and 6 juveniles, while the group kept at Newquay Zoo in Newquay consisted of

1508 related subjects, of which 3 were adults and 5 juveniles. All juveniles were 6 to 12 months old

151 (see Table S1). Otters were identified by distinctive markings on their face and body. The groups

152 differed in their regular feeding regime; at Tamar, food was provided at variable times of day and

153 their diet (standardised in weight) consisted of various food items, including whiting, clams,

154 oysters and fish-based biscuits. Occasionally the keepers would introduce chicks, helmeted guinea

155 fowl and queen scallops. The feeding regime at Newquay followed a strict schedule, with the

156 group being fed at 9 AM, 12 AM, 4 PM and 6 PM, and their diet consisted of chicks, mice,

157 minced beef meatballs and hard-boiled eggs. The observations and experiments described below

158 took place from March to May 2018.

\section{Experimental food presentations}

160 To investigate how food sharing and harassment would vary with food-extraction complexity and

161 food abundance, we conducted 9 experimental food presentations per group. The two otter groups

162 were tested within their normal zoo enclosures. Prior to experimental trials, otters in Newquay

163 were fed $\sim 14-20$ chicks for their 9 AM feed, and 8 mice, 6 hard-boiled eggs and 8 minced beef

164 balls for their midday feed. The Tamar group varied in their feeding times throughout the day. 
165 However, they were always fed whiting and fish biscuits at midday prior to the experimental

166 treatments. The experimental treatments took place at least one hour after the otter's regular

167 feeding times and were undertaken between 12-4 PM. This limited any food-driven anticipatory

168 behaviour and fullness from a previous feed.

169 We varied food complexity by presenting three natural prey types: rainbow trout

170 (Oncorhynchus mykiss), shore crab (Carcinus maenas) and blue mussels (Mytilus edulis), which

171 we presented on consecutive days in a randomised order. Shore crabs averaged $8 \mathrm{~cm}$ in diameter

172 and the rainbow trout were cut into $5 \mathrm{~cm}$-width pieces. These food types were novel to the

173 Newquay group and represented a non-regular prey type to the Tamar group. The hard shells of

174 shore crabs and mussels required dexterous manipulation by otters to exploit, whereas the soft

175 flesh and lack of protective shell made trout an easily exploitable food type. We inferred food type

176 complexity by the amount of time otters spent to exploit each food item, measured for five adults

177 and five juveniles in each otter group (i.e., $n=20$ observations per food type) from first touch to

178 consumption of the piece of food. This confirmed that trout was the easiest (i.e., fastest) to exploit

179 (average latency +/- SD (seconds): $80.83+/-32.58 \mathrm{~s})$, followed by mussels $(112.75+/-45.46 \mathrm{~s})$,

180 with crabs taking the longest to consume $(224.96+/-93.55 \mathrm{~s})$. The abundance of each prey type

181 was manipulated to be either half as many food items as there were otters (low), the same number

182 of food items as there were otters (medium) or double the number of food items as there were 183 otters (high).

184 Each otter group experienced one trial per day, starting with prey of medium complexity,

185 then hard, then easy to exploit, in either low, medium or high abundances (in a randomised order)

186 until all 9 trials (representing all possible combinations of food type and abundance) were

187 completed. Due to only two otter families being studied, food type was not randomised across 
188 groups to avoid confounding group ID and food type order. After conducting the three different

189 abundance trials per food type, there was an inter-trial interval of 2-5 days. This interval was

190 implemented to reduce anticipatory behaviour towards the trials, which could have influenced the

191 otters' behaviours. For each trial, the zookeepers would close the otters inside their pen whilst we

192 placed the food at random locations within the same 3 × $3 \mathrm{~m}$ vicinity inside the otter enclosure for

193 each treatment. Once the otters were released, we filmed the group until all food items were

194 consumed. We filmed all trials with three video cameras placed such that they covered the whole

195 enclosure area.

\section{Video analyses}

197 We scored all videos of experimental food presentations using the definitions adapted from de

198 Waal (1997). A 'beggar' was defined as any individual that approached within an 'otter's arm's

199 length' of the 'food owner', while making vocal solicitations.

\section{Food sharing behaviours}

201 (i) collect near: beggar retrieves food item from near owner's arms, or within an otter's arm

202 length of owner. There is no retaliation from the food owner when food item is taken;

203 (ii) relaxed claim: beggar takes part of the food, or the whole food item that the food owner

204 possesses (i.e., in the owner's paws) without resistance from owner;

205 (iii) food giving: owner facilitates transfer of food by actively moving it toward beggar.

206 Harassment behaviours

207 (iii) passive begging: beggar sits near and stares at the food owner (no physical contact), within

208 ca. $\leq 1 \mathrm{~m}$ of food owner. The beggar will often be in the owner's view, but the beggar can sit and 
209 stare from behind, commonly whilst making long, repetitive vocalisations directed at the food

210 owner.

211 (iv) active begging: beggar physically contacts owner or food. The owner has full view of the

212 beggar, and the beggar's paws are either on the food item itself, or on the food owner's paws.

213 Active begging can be distinguished from an attack or other aggressive interactions as the latter

214 involved lunges with or without physical contact (e.g., grabbing the other's side of their neck with

215 their teeth). Aggressive interactions or attacks were exceedingly rare and usually lasted no longer

216 than 10 seconds.

217

218 We scored the number of sharing and harassment behaviours for each individual in each food

219 presentation trial video. The food sharing behavioural category 'collect near' (e.g., collecting food

220 scraps or broken off pieces within an otter's arm's length of a feeding individual) was included in

221 the analysis as a voluntary food transfer; in each instance when an otter was successful, and

222 collected a piece of food near the owner, there was clear possession of food by the owner. On

223 occasions when 'collect near' was unsuccessful, i.e., the approaching otter tried but failed to

224 collect a nearby piece of food, the food owner responded by either collecting the nearby piece

225 themselves and turning away, turning their head to stare at the approaching otter, or engaging in a

226 lunge towards the approaching otter. This suggested that, by reacting to the approaching otter's

227 presence, the food owner regarded the nearby food item as within their possession.

228 This categorisation of food sharing and begging behaviours is commonly used to examine food

229 interactions and strategies (Boesch and Boesch 1989; de Waal 1989, 1997a, b; Stevens 2004; de

230 Waal 1993). We also recorded any harassment behaviours that resulted in food transfers and the

231 IDs of the initiator and receiver of food transfers. Coding of the videos started when the first piece 
232 of food was touched by an individual and ended when all food items were eaten or after 45

233 minutes of food exposure.

\section{Statistical analyses}

235 All analyses of begging and sharing behaviours were performed in R 3.6.1 (R Development Core

236 Team 2019) using generalised linear mixed-effect models (GLMMs) implemented in the lme4

237 package (Bates et al. 2014). The total number of active and passive begging occurrences (the most

238 common type of harassment behaviours observed), and the sum of all types of voluntary sharing

239 behaviours (i.e., collect near, relaxed claim and food giving), per otter and trial duration were

240 modelled assuming a Poisson error distribution and using a log link function. Trial duration

241 measured in minutes was log-transformed and included as an offset term

242 (offset $(\log ($ trialduration/60) )) to account for the variable lengths of each food presentation trial,

243 effectively transforming the number of begging and sharing events into a begging and sharing rate

244 (the number of events per hour). To account for overdispersion, we included an observation-level

245 random effect (OLRE) (Harrison 2014). Furthermore, to control for repeated measures of the

246 same 20 individuals, and for the fact that we recorded the behaviour of all individuals within each

247 of 18 experimental trials ( 9 per zoo), we included both otter ID and trial number as random effects

248 in our model structure. To test for the overall significance of our key predictors, we compared the

249 full models with respective null models using a Likelihood ratio test (hereafter LRT), using the

250 LRT R function “drop1 ” with argument 'test' set to 'Chi' (Bates et al. 2014; Dobson 2002).

251 Firstly, to test if otters were more likely to share if they received more begging, which

252 would support the harassment avoidance hypothesis, we constructed a GLMM with Poisson error

253 distribution using the total number of 'food transfers' (i.e., both voluntarily and following

254 harassment) for each food presentation trial for each otter as our response variable. We fitted the 
255 total number of instances of 'begging received' per otter per trial, and the offset for trial duration,

256 as our only fixed effects. We included the observation-level random effect as well as otter ID and

257 trial as random effects.

258 Before testing whether food type, food abundance, otter sex and age affected begging

259 frequency, we first checked whether juvenile otters were less efficient foragers than adults, and

260 whether any difference in foraging efficiency between age categories increased with food type

261 complexity. Such age differences in foraging efficiency might then explain age differences in

262 begging frequencies. We analysed the five (randomly selected) observations of food exploitation

263 latency per otter age category per food type per zoo with a linear mixed-effects model (LMM).

264 The response variable was the log-transformed latency to exploit the food type from first touch to

265 complete ingestion, while the fixed effects were food type, age category and their interaction. Zoo

266 ID was included as a random effect.

267 We then constructed a Poisson-GLMM with the total number of active and passive

268 begging occurrences per food presentation trial per otter as the response variable. Food type

269 (crabs, mussels or trout), food abundance (low, medium or high), as well as sex, otter age category

270 (juvenile or adult), zoo and the offset for trial duration were included as fixed effects, and we

271 included the observation-level identifier, otter ID and trial as random effects. To improve

272 convergence, we used the "BOBYQA" optimizer. To test whether the same predictors affected

273 food sharing frequencies, we ran the exact same model, but using the total number of sharing

274 occurrences per food presentation trial per otter as the response variable.

275 To test if the age composition of food owner-receiver dyads influenced the frequency of

276 voluntary sharing, we fitted another Poisson-GLMM using the number of directional voluntary

277 sharing occurrences summed for each potential dyad in each otter group across all trials and 
278 treatments as our response variable. We fitted the age composition of the otter dyad (i.e., Adult

279 sharing with Adult, Juvenile-Juvenile, Adult-Juvenile or Juvenile-Adult) and the offset for trial

280 duration as our fixed effects. We included the observation-level random effect as well as the ID of

281 the sharing individual and the ID of the receiving individual as our random effects. We also

282 performed the post-hoc Tukey multiple comparison test to compare the different age composition-

283 dyads for significant differences in directional sharing frequencies.

284 To detect and identify any outliers within our models, we used an exploratory analysis

285 approach where we calculated the interquartile range for our non-normally distributed response

286 residuals and the upper and lower Tukey fences (upper fence; Q3 $+1.5 *$ IQR, lower fence $=\mathrm{Q} 1$

$287-1.5 *$ IQR; Tukey 1977) to determine any data points outside of this range. Of 20 subjects,

288 there were 12 individuals within our 'total number of begging occurrences' variable that were

289 considered to be outliers. These 12 individuals were all juveniles ( $\leq 12$ months). Our 'total

290 number of sharing occurrences' revealed 1 individual to be an outlier, our 'total number of food

291 transfers' revealed no outliers and our 'total times that begging was received' contained 11

292 individuals classed as outliers. The extreme values, or 'outliers' in our 'total number of begging

293 occurrences' were all generated by juveniles and the extreme values in our 'total times that

294 begging was received' were mostly adults being begged to. This indicated that there were age

295 group differences and thus, all 'outliers' were included in our analyses (code available on

296 Figshare and see Table S2, S3 and S4 for results excluding 'outliers').

297 Results

298 Is begging correlated with food transfers?

299 There was a positive relationship between the frequency with which otters received begging and

300 the number of times they transferred food: the more begging individuals received, the more often 
301 they transferred food (Table 1, Fig. 1; LRT for begging received: $X^{2}$ (1) $13.19, P=<.001 ; 95 \%$

302 confidence interval [CI] 0.04-0.14). Effect size estimates showed that for every begging bout,

303 otters were estimated to receive on average 1.6 food transfers (ranging from 0.55-3.31 for the

304 shortest and longest trial durations, respectively).

\section{Do food type and abundance affect begging and sharing frequencies?}

307 Juveniles took significantly longer than adults to exploit the experimentally provided foods (LRT

308 for age category: $\left.X^{2}(1)=9.75, P=0.002\right)$. However, this difference in foraging efficiency

309 between juveniles and adults did not increase with food type complexity (LRT for food type-age

310 interaction: $X^{2}(2)=0.40, P=0.82$ ). Across age categories, food type did not significantly affect

311 otters' begging rates (LRT for food type: $X^{2}(2)=3.60, P=0.17 ; 95 \%$ confidence interval food

312 type trout $[\mathrm{CI}]-1.20-0.22 ; 95 \%$ confidence interval food type mussel [CI] -1.37-0.05). Although

313 otters appeared to beg less when more food was available (Table 2, Fig. 2), food abundance did

314 not significantly affect otters' begging rates either (LRT for food abundance: $X^{2}(2)=4.09, P=$

$3150.13 ; 95 \%$ confidence interval high food abundance [CI] $-1.40-0.05 ; 95 \%$ confidence interval

316 medium food abundance [CI] -0.76-0.64).

317 Neither food abundance nor food type affected otters'sharing rates (Table 3; LRT for

318 food abundance: $X^{2}(2)=1.79 P=0.41 ; 95 \%$ confidence interval high food abundance [CI] -

$3190.33-0.86 ; 95 \%$ confidence interval medium food abundance [CI] -0.21-0.99). LRT food type: $X^{2}$

$320(2)=0.92, P=0.63 ; 95 \%$ confidence interval food type trout $[\mathrm{CI}]-0.56-0.64 ; 95 \%$ confidence

321 interval food type mussel [CI] -0.78-0.38; Table 3). 
322 Do otter age, zoo and sex correlate with begging and sharing frequencies?

323 Juveniles begged significantly more than adults over all trials (Table 2, Fig. 3; LRT for age

324 category: $X^{2}(1)=7.53, P=0.006 ; 95 \%$ confidence interval juveniles $\left.[\mathrm{CI}] 0.21-1.10\right)$. There

325 were no significant effects of otter sex or zoo on begging frequencies (LRT for zoo: $X^{2}(1)=$

$3262.67, P=0.10$, sex: $X^{2}(1)=0.04, P=0.84 ; 95 \%$ confidence interval Tamar group $[\mathrm{CI}]-0.12-$

327 1.17; 95\% confidence interval sex: male [CI] -0.40-0.48). Effect size estimates showed that for

328 each time an adult begged, juveniles begged 2.19 times (ranging from 0.73-4.40 for shortest and

329 longest trial durations). We found that juveniles shared significantly less than adults over all

330 trials (Table 3, Fig. 4; LRT for age category; $X^{2}(1)=12.85, P=<.001$; 95\% confidence interval

331 juveniles [CI] -1.29- -0.43). An overall effect size estimate of 0.77 showed that juveniles shared

332 ca. $23 \%$ less than adults (ranging from $0.26-1.55$ for shortest and longest trial durations,

333 respectively). There was no significant effect of zoo or otter sex on sharing frequency (LRT for

334 zoo: $X^{2}(1)=0.39, P=0.53$, sex: $X^{2}(1)=0.53, P=0.47 ; 95 \%$ confidence interval Tamar group

$335[\mathrm{CI}]-0.75-0.39 ; 95 \%$ confidence interval sex: male $[\mathrm{CI}]-0.57-0.29)$.

336 The age composition of otter dyads had a significant effect on sharing (LRT for sharing

337 dyad age composition: $\left.X^{2}(3)=13.179, P=0.004\right)$; juvenile dyads $(\mathrm{J}-\mathrm{J})$ shared significantly less

338 than adult dyads (A-A) (Tukey post-hoc test, $P=0.034$ ) and juveniles shared significantly less

339 with adults than adults did with each other (Tukey post-hoc test, $P=<.001$ ). All other

340 comparisons of age composition were not significant ( $>0.05$ ) (see Table 4, Fig. 5).

341 Discussion

342 Harassment avoidance or 'sharing-under-pressure'

343 Otters showed both passive and active begging during our experimental trials, and food owners

344 responded to both forms of harassment (i.e., behaviours that restrict the food owner's ability to

345 eat their food in peace) by sharing their food. This suggests that harassment is costly to the food 
346 owner, and that this cost forces them to share instead. Our results thus provide support for the

347 harassment avoidance/sharing-under-pressure hypothesis, which assumes begging imposes high

348 energetic and opportunity costs on the food owner (Stevens and Stephens 2002; Wrangham

349 1975). While harassment hence seems to be a parsimonious explanation for the food sharing

350 observed in our captive otter family groups, the drivers of food sharing in this species could be

351 further explored. For example, one could experimentally vary the ease with which food items can

352 be monopolised, as well as quantify the relative costs of begging and sharing food.

\section{Begging behaviour and food type/abundance treatments}

354 Although begging was somewhat less frequent when food was abundant, neither food type nor

355 abundance had a significant effect on begging or sharing frequencies. Captive otters often show

356 incessant begging, which has been proposed to be related to excessive hunger (Gothard 2007)

357 and/or boredom (Hawke et al. 2000). Excessive hunger seems an unlikely cause of the otters'

358 begging behaviour, given that zoos follow guidelines of adequate nutrition, diets and feeding

359 regimes, and part of the otters' daily diet is often used as enrichment to encourage natural

360 foraging skills and reduce boredom (IUCN/SSC Otter Specialist Group 2012). However, it

361 should also be noted that the exact nutrient requirements for captive otters are still unknown and

362 these guidelines can vary dramatically between species and institutions (IUCN/SSC Otter

363 Specialist Group 2012; Lombardi 2002).

364 Wild otters have a high metabolic rate and spend up to $60 \%$ of their time foraging (Davis

365 et al. 1992; Marshall et al. 1988; Spelman 1999; Hoover and Tyler 1986). Their diet is nutrient-

366 dense, and wild otters eat small amounts and frequently (IUCN/SSC Otter Specialist Group

367 2012; Marshall et al. 1988). For a species with such a high energy requirement and an

368 opportunistic foraging strategy, we expected to see an increase in begging behaviour during our 
369 low food abundance treatment. Although food limitation can increase begging frequencies in

370 some food-sharing species (Quillfeldt and Masello 2004; Price and Ydenberg 1995; Smith and

371 Montgomerie 1991), occurrences of begging in other species appear to be independent of food

372 availability and ownership (Kuroda 1984). Here, we observed otters begging across all food

373 abundance conditions and regardless of food ownership.

374 Our experimental manipulation of food type also did not appear to affect begging or

375 sharing frequencies, which might be due the fact that most otter species are generalists (Timm-

376 Davis et al. 2015), and their diets reflect the local abundance of food (Almeida et al. 2012;

377 Clavero et al. 2003; Krpo-Ćetković et al. 2019; Lanszki and Körmendi 1996). Asian small-

378 clawed otters are manual predators who rely on extractive foraging, using their clawless fingers

379 to reach into crevices and sieve through silt (Ladds et al. 2017). Their jaws are well equipped to

380 crack hard shells compared to other mouth-oriented species and their partially webbed paws

381 allow for greater dexterity (Sivasothi and Nor 1994; Timm-Davis et al. 2015). Although all of

382 the food types used in this study represented novel prey to the captive otters we tested, they are

383 part of a typical diet for wild Asian-small clawed otters (Chanin 1985; Mason and Macdonald

384 1987). This adaptation to a generalist diet (Timm-Davis et al. 2015) could partly explain why

385 food type had no effect on begging frequency in this study.

\section{Begging behaviour and otter age}

387 Juveniles exhibited more begging behaviour than adults, and within the group of juveniles, the

388 youngest individuals begged more than others. Explanations for juveniles begging for food have

389 centred around begging being an honest signal of hunger (Bowers et al. 2019; Kilner and

390 Johnstone 1997; Godfray 1991; Mock and Parker 1997) and competition between siblings

391 (Harper 1986; Stamps, Metcalf and Krishnan 1978; Macnair and Parker 1979; Parker 1985). 
392 According to the honest signalling hypothesis (Bowers et al. 2019; Kilner and Johnstone 1997;

393 Godfray 1991; Mock and Parker 1997), the costly qualities of extravagant begging behaviours

394 advertise an offspring's current nutritional need (Cotton et al. 1996; Kilner 1995; Kilner and

395 Johnstone 1997; Ottoson et al. 1997). However, this idea remains somewhat controversial (Mock

396 et al. 2011; Parker et al. 2002), and others have argued that stronger, rather than hungrier,

397 individuals can maintain higher and longer levels of begging (Grafen 1990; Parker et al. 2002).

398 In captive Asian small-clawed otters, behaviours such as food handling, chewing and

399 swallowing are energetically expensive (Borgwardt and Culik 1999), and in some otter species,

400 juveniles have similar mass-specific energy demands as adults (sea otters: Thometz et al. 2014).

401 In addition to needing food constantly, foraging skills in some species of otters do not fully

402 develop until 13 months old (Watt 1991; 1993). In our study, the most frequently begging

403 individuals were $\sim 3-12$ months old. Perhaps, the extensive begging displayed by these young

404 individuals was indeed an honest signal of hunger, reinforced by competition with older siblings

405 (Field et al. 2005). Moreover, the higher begging frequencies in these young individuals could

406 also be influenced by foraging incompetence, and thus their dependence on older offspring and

407 adults for the acquisition of food (Jaeggi et al. 2008), as we found that juveniles were less

408 efficient foragers than adults across all food types. This difference in foraging competence might

409 also help explain why we observed less food sharing between juveniles and from juveniles to

410 adults as compared to adult dyads (see below).

\section{Food sharing behaviour, food type/abundance treatments and the effect of age}

412 Food sharing frequencies have been observed to differ between food types in some species,

413 including chimpanzees (Boesch and Boesch 1989; Rose 1997) and capuchins (de Waal 2000),

414 but not in others (Kuroda 1984; bonobo). Although food abundance and quality thus have the 
415 potential to influence some food sharing instances in nature (Elgar 1986), we did not find an

416 effect of food abundance nor food type on sharing frequency. Our study suggests that these

417 ecological factors appear to have little influence on food sharing in Asian small-clawed otters.

418 This may be due to the fact that we studied otters in captivity; given that captive animals get

419 provisioned several times per day, our food manipulations may have been less relevant and

420 effective than if we had been able to study more food-motivated individuals in the wild.

$421 \quad$ Although food abundance and type did not influence sharing frequencies, we found that

422 juvenile otters shared food significantly less often than did adults. Older animals tend to be more

423 skilled and efficient at catching prey compared to juveniles (Goss-Custard and Durell 1987;

424 Stalmaster and Gessamen 1984; Woo et al. 2008) and the inefficiency of juveniles' foraging

425 behaviour can lead to intra-specific competition with older individuals (Field et al. 2005). In sea

426 otters, juveniles are proficient at tool use and prey handling by 5 months of age, while juveniles

427 in other hand-oriented otter species are proficient only at 13 months of age (Payne and Jameson

428 1984; Watt 1991; 1993). It is possible that the youngest individuals in our study were in

429 competition with adults and older siblings for the acquisition of food, and were thus less inclined

430 to share food, while the highly competent adult foragers could afford to share. It would be of

431 value for future studies to examine age-class influences on food competition and food transfer

432 behaviours in more detail.

\section{Conclusion}

434 The experiments presented in this study provide the first exploration and insights into food

435 sharing and the use of begging behaviours in the Asian small-clawed otter. We found that otters

436 are more likely to share food with increased harassment, in the form of begging behaviours,

437 supporting the harassment avoidance/sharing-under-pressure hypothesis. Furthermore, we found 
438 evidence that juveniles shared less and begged more than adults, with the youngest juveniles

439 begging more than the others. However, food abundance and food type appear to have little

440 influence on food sharing and begging behaviours in Asian small-clawed otters. It is important to

441 note that this may be due to the fact that our subjects were in a captive setting, and thus our food

442 manipulations may be less effective than they might be in wild and more food-motivated

443 individuals. This study had a relatively small sample size and it is essential to repeat this study

444 on more groups of otters with a larger range of ages and group sizes. The frequent begging

445 behaviours observed during this study, and the considerable variation in begging across age

446 groups, also warrant further study. In addition, we suggest that further investigation of food

447 sharing in Asian small-clawed otters considers the influence of social bonds on food transfers, as

448 social dominance, partner-choice and social network structure might help further explain food

449 sharing in this highly sociable species.

\section{Acknowledgements}

453 We thank Newquay Zoo and Tamar Otter and Wildlife Centre for access to their otter groups.

454 We also thank The University of Exeter for the loan of equipment and Georgina Hume, Tiffany

455 Volle and Alex Saliveros for their field assistance.

\section{References}

461 
462 Almeida, D., Copp, G.H., Masson, L., Miranda, R., Murai, M. and Sayer, C.D. 2012.

463 Changes in the diet of a recovering Eurasian otter population between the 1970s and 2010.

464 Aquatic Conservation: Marine and Freshwater Ecosystems. 22. 26-35.

465

466 Aziz, M.A. 2018. Notes on Population Status and Feeding Behaviour of Asian Small-Clawed

467 Otter (Aonyx cinereus) in the Sundarbans Mangrove Forest of Bangladesh. IUCN Otter Spec.

468 Group Bull. 35:3-10.

469

470

Bachman, G.C. and Chappell, M.A. 1998. The energetic cost of begging behaviour in nestling house wrens. Animal Behaviour. 55:607-1618.

472

Bates, D., Maechler, M., Bolker, B. and Walker, S. 2014. lme4: Linear mixed-effects models using Eigen and S4 (Version 1.0-6). March 2019. http://CRAN. Rproject. org/package=lme4.

475

476

477

478

479

480

481

482

483

484 Accessed March 2020.

Blurton Jones, N.G. 1987. Tolerated theft, suggestions about the ecology and evolution of sharing, hoarding and scrounging. Information (International Social Science Council). 26: 31-54.

Boesch, C. and Boesch, H. 1989. Hunting behavior of wild chimpanzees in the Tai National Park. American journal of physical anthropology. 78: 547-573.

Boesch, C., Hohmann, G. and Marchant, L. (eds.) 2002. Behavioural diversity in chimpanzees and bonobos. Cambridge University Press, Cambridge, United Kindom. 
485

486 Boggs, C.L. 1995. Male nuptial gifts: phenotypic consequences and evolutionary implications.

487 Pp 215-242 in insect reproduction (S.R. Leather and J. Hardie ed). CRC Press. United States.

488

489 Bolnick, D.I., Svanbäck, R., Fordyce, J.A., Yang, L.H., Davis, J.M., Hulsey, C.D. and Forister,

490 M.L. 2003. The ecology of individuals: incidence and implications of individual

491 specialization. The American Naturalist. 161:1-28.

492

493 Bolten, A.B., Robinson, F.A., Nation, J.L. and Yu, S.J. 1983. Food Sharing Between Honeybee

494 Colonies in Flight Cages. Journal of Apicultural Research. 22:98-100.

495

496 Borgwardt, N. and Culik, B.M. 1999. Asian small-clawed otters (Amblonyx cinerea): resting and

497 swimming metabolic rates. Journal of Comparative Physiology B. 169:100-106.

498

499 Bowers, E.K., Jenkins, J.B., Mueller, A.J., Miller, K.D., Thompson, C.F. and Sakaluk, S.K.

500 2019. Condition-dependent begging elicits increased parental investment in a wild bird

501 population. The American Naturalist. 193:725-737.

502

503 Brownell, C.A., Svetlova, M. and Nichols, S. 2009. To share or not to share: When do toddlers

504 respond to another's needs?. Infancy. 14: 117-130.

505

506 Brown, G.R., Almond, R.E. and Bergen, Y.V. 2004. Begging, stealing, and offering: food

507 transfer in nonhuman primates. Advances in the Study of Behaviour. 34:265-295. 
509 Brown, G.R., Almond, R.E. and Bates, N.J. 2005. Adult-infant food transfer in common

510 marmosets: an experimental study. American Journal of Primatology: Official Journal of the

511 American Society of Primatologists. 65: 301-312.

512

513 Budden, A.E. and Wright, J. 2001. Begging in nestling birds. Pp 83-119 in Current ornithology

514 (V. Nolan Jr and F. Charles, eds.). Springer, Boston, Massachusetts.

515

516

517 Carter, G.G., Farine, D.R., Crisp, R.J., Vrtilek, J.K., Ripperger, S.P. and Page, R.A. 2020.

518 Development of new food-sharing relationships in vampire bats. Current Biology. 30: 1275-

5191279.

520

521 Carter, G.G. and Wilkinson, G.S. 2013. Food sharing in vampire bats: reciprocal help predicts 522 donations more than relatedness or harassment. Proceedings of Royal Society B. 280: 1-6.

523

524 Capodeanu-Nägler, A., Eggert, A.K., Vogel, H., Sakaluk, S.K. and Steiger, S. 2017. Species

525 divergence in offspring begging and parental provisioning is linked to nutritional

526 dependency. Behavioral Ecology. 29:42-50.

527

528 Chanin, P. 1985. The natural history of otters. Pp 179-180 in Fact on File. Oxford. London, 529 Croom Helm.

530 
531 Christe, P., Richner, H. and Oppliger, A. 1996. Begging, food provisioning, and nestling

532 competition in great tit broods infested with ectoparasites. Behavioral Ecology. 7:127-131.

533

534 Clavero, M., Prenda, J. and Delibes, M. 2003. Trophic diversity of the otter (Lutra lutra) in

535 temperate and Mediterranean freshwater habitats. Journal of Biogeography. 30:761-769.

536

537 Clutton-Brock, T. 2009. Cooperation between non-kin in animal societies. Nature. 462:51-52.

538

539 Cooper, S.M. 1991. Optimal hunting group size: the need for lions to defend their kills against

540 loss to spotted hyaenas. African Journal of Ecology. 29:130-136.

541

542 Costa, D.P. and Kooyman, G.L. 1982. Oxygen consumption, thermoregulation, and the effect of

543 fur oiling and washing on the sea otter, Enhydra lutris. Canadian Journal of Zoology. 60:2761-

5442767.

545

546 Dale, R., Range, F., Stott, L., Kotrschal, K. and Marshall-Pescini, S. 2017. The influence of

547 social relationship on food tolerance in wolves and dogs. Behavioral ecology and

548 sociobiology. 71:2-12.

549

550 Davis, H.G., Aulerich, R.J., Bursian, S.J., Sikarskie, J.G. and Stuht, J.N. 1992. Feed consumption

551 and food transit time in northern river otters (Lutra canadensis). Journal of Zoo and Wildlife

552 Medicine. 1:241-244.

553 
554 De Kort, S.R., Emery, N.J. and Clayton, N.S. 2006. Food sharing in jackdaws, Corvus monedula:

555 what, why and with whom?. Animal Behaviour. 72:297-304.

556

557 DeNault, L.K. and McFarlane, D.A. 1995. Reciprocal altruism between male vampire bats, 558 Desmodus rotundus. Animal Behaviour. 49:855-856.

559

560 De Waal, F.B. (ed.). 1996. Pp 132-1136 in Good natured. Harvard University Press. Cambridge, 561 London.

562

563 De Waal, F.B. 1997a. The chimpanzee's service economy: food for grooming. Evolution and 564 Human Behaviour. 18:375-386.

565

566 De Waal, F. B. 1997b. Food transfers through mesh in brown capuchins. Journal of Comparative 567 Psychology. 111:370-378.

568

569

570

De Waal, F.B. 1989. Food sharing and reciprocal obligations among chimpanzees. Journal of

571 Human Evolution. 18:433-459.

572

573 De Waal, F.B. 2000. Attitudinal reciprocity in food sharing among brown capuchin monkeys. 574 Animal Behaviour. 60:253-261.

575

576 De Waal, F.B. and Berger, M.L. 2000. Payment for labour in monkeys. Nature. 404:563-564. 
578 Dobson, A. J. 2002. An introduction to generalized linear models. (2nd, ed). CRC Press, Boca

579 Raton.

580

581 Elgar, M.A. 1986. The establishment of foraging flocks in house sparrows: risk of predation and 582 daily temperature. Behavioral Ecology and Sociobiology. 19:433-438.

583

584 Evans, C.S. and Marler, P. 1994. Food calling and audience effects in male chickens, Gallus

585 gallus: their relationships to food availability, courtship and social facilitation. Animal

586 Behaviour. 47:1159-1170.

587

588

Fedorowicz, S.M., Beard, D.A. and Connor, R.C. 2003. Food sharing in wild bottlenose dolphins. Compartimiento de alimento en delfines bufeos silvestres. Aquatic Mammals. 29:355-

590 359.

591

592 Feistner, A.T.C. and McGrew, W.C. 1989. Food-sharing in primates: a critical 593 review. Perspectives in primate biology. 3:21-36.

594

595 Feistner, A.T.C. and Chamove, A.S. 1986. High motivation toward food increases food-sharing 596 in cotton-top tamarins. Developmental Psychobiology: The Journal of the International Society 597 for Developmental Psychobiology. 19: 439-452.

598

599 Feistner, A.T.C and Price, E.C. 1990. Food-sharing in cotton-top tamarins (Saguinus

600 oedipus). Folia primatological. 54:34-45. 
601

602 Feistner, A.T. and Price, E.C. 2000. Food sharing in black lion tamarins (Leontopithecus

603 chrysopygus). American Journal of Primatology: Official Journal of the American Society of

604 Primatologists. 52:47-54.

605

606 Field, I.C., Bradshaw, C.J., Burton, H.R., Sumner, M.D. and Hindell, M.A. 2005. Resource

607 partitioning through oceanic segregation of foraging juvenile southern elephant seals (Mirounga

608 leonina). Oecologia. 142: 127-135.

609

610 Foster-Turley, P. 1992. Conservation aspect of the ecological of Asian small-clawed otter and

611 Smooth-coated otter on the Malay Peninsula. IUCN Specialist Group Bull. 7:26-29.

612

613 Gilby, I.C. 2006. Meat sharing among the Gombe chimpanzees: harassment and reciprocal

614 exchange. Animal Behaviour. 71:953-963.

615

616 Goodall, J. 1986. The chimpanzees of Gombe: Patterns of behavior. Harvard University Press,

617 Cambridge. The Journal of Tropical Ecology. 3:190-191.

618

619 Godfray, H.C.J. 1991. Signalling of need by offspring to their parents. Nature. 352:328-330.

620

621 Godfray, H.C.J. 1995. Signaling of need between parents and young: parent-offspring conflict 622 and sibling rivalry. The american naturalist. 146:1-24.

623 
624 Goss-Custard, J.D. and Durell, S.L.V.D. 1987. Age-related effects in oystercatchers,

625 Haematopus ostralegus, feeding on mussels, Mytilus edulis. I. Foraging efficiency and

626 interference. The Journal of Animal Ecology. 1:521-536.

627

628 Grafen, A. 1990. Biological signals as handicaps. Journal of theoretical biology. 144:517-546.

629

630 Griffiths, S.W. and Armstrong, J.D. 2002. Kin-biased territory overlap and food sharing among 631 Atlantic salmon juveniles. Journal of Animal Ecology. 71:480-486.

632

633 Hadjichrysanthou, C. and Broom, M. 2012. When should animals share food? Game theory

634 applied to kleptoparasitic populations with food sharing. Behavioral Ecology. 23:977-991.

635

636 Hamilton, W. D. 1964 The genetical evolution of social behaviour. Theoretical Biology. 7:1-52. 637

638 Harper, A.B., 1986. The evolution of begging: sibling competition and parent-offspring conflict.

639 The American Naturalist. 128:99-114.

640

641 Harrison, X.A. 2014. Using observation-level random effects to model overdispersion in count

642 data in ecology and evolution. PeerJ. 2:e616. DOI 10.7717/peerj.616.

643

644 Hauser, M.D. 1992. Costs of deception: cheaters are punished in rhesus monkeys (Macaca 645 mulatta). Proceedings of the National Academy of Sciences. 89:12137-12139. 
647 Hauser, M.D. and Marler, P. 1993. Food-associated calls in rhesus macaques (Macaca mulatta):

648 II. Costs and benefits of call production and suppression. Behavioral Ecology. 4:206-212.

649

650 Hawke, L., Lauer, P., Bartholomeusz, D. and Steen, Z. 2000. Effects of increased food dispersal 651 and random feeding time/place on stereotyped behaviours in otters at Adelaide Zoo. International 652 Zoo News. 47:71-81.

653

654 Heinrich, B. 1988. Winter foraging at carcasses by three sympatric corvids, with emphasis on 655 recruitment by the raven, Corvus corax. Behavioral Ecology and Sociobiology, 23:141-156. 656

657 Hiraiwa-Hasegawa M. 1990. Role of food sharing between mother and infant in the ontogeny of 658 feeding behavior. Pp 267-275 in The chimpanzees of the Mahale Mountains: sexual and life 659 history strategies. (Nishida T, eds.). Tokyo: University of Tokyo Press.

660

661 Holekamp, K.E. and Smale, L. 1990. Provisioning and food sharing by lactating spotted hyenas, 662 Crocuta crocuta. Ethology. 86:191-202.

663

664 Hoelzel, A.R. 1991. Killer whale predation on marine mammals at Punta Norte, Argentina; food 665 sharing, provisioning and foraging strategy. Behavioral Ecology and Sociobiology. 29:197-204.

666

667 Hoover, J.P. and Tyler, R.D. 1986. Renal function and fractional clearances of American river 668 otters (Lutra canadensis). Journal of Wildlife Diseases. 22:547-556. 
670 Isaac, G. 1978. The food-sharing behavior of protohuman hominids. Scientific American. 238:

$67190-109$.

672

673 IUCN/SSC Otter Specialist Group. 2012. Summary of Nutrition Guidelines for Otters in Zoos, 674 Aquaria, Rehabilitation, and Wildlife Sanctuaries. Online. IUCN/SSC Otter Specialist Group, 675 Otters in Zoos, Aquaria, Rehabilitation, and Wildlife Sanctuaries (OZ) Task Force. 1-26. 676

677 Jaeggi, A.V., Van Noordwijk, M.A. and Van Schaik, C.P. 2008. Begging for information:

678 mother-offspring food sharing among wild Bornean orangutans. American Journal of

679 Primatology: Official Journal of the American Society of Primatologists. 70:533-541.

680

681 Jaeggi, A.V. and Van Schaik, C.P. 2011. The evolution of food sharing in primates. Behavioral 682 Ecology and Sociobiology. 65:2125-2140.

683

684 Johnson, R.H. 1982. Food-sharing behavior in captive Amazon River dolphins (Inia geoffrensis). 685 Biological Systems. 43:1-3.

686

687 Jones, N.B. 1984. A selfish origin for human food sharing: tolerated theft. Ethology and 688 sociobiology. 5:1-3.

689

690 Kaplan, H., Gurven, M., Hill, K. and Hurtado, A.M. 2005. The natural history of human food 691 sharing and cooperation: a review and a new multi-individual approach to the negotiation of 
692 norms. Moral sentiments and material interests: The foundations of cooperation in economic life. 693 6:75-113.

694

695 Karasov, W.H. and Wright, J. 2002. Nestling digestive physiology and begging. Pp 199-219 in

696 The Evolution of Begging (J. Wright and M.L. Leonard, eds.). Springer, Dordrecht.

697 Kenyon, W. 1969. The sea otter in the eastern Pacific Ocean. North American Fauna. 68:1-352.

698

699 Kilner, R. 1995. When do canary parents respond to nestling signals of need?. Proceedings of the

700 Royal Society of London. Series B: Biological Sciences. 260: 343-348.

701

702 Kilner, R. and Johnstone, R.A. 1997. Begging the question: are offspring solicitation behaviours 703 signals of need?.Trends in Ecology \& Evolution. 12:11-15.

704

705 Krpo-Ćetković, J., Subotić, S., Skorić, S. and Ćirović, D. 2019. Diet of the Eurasian otter (Lutra 706 lutra) on the River Gradac, Serbia: Predation in a brown trout-dominated stream. Aquatic 707 Conservation: Marine and Freshwater Ecosystems. 29:282-291.

708

709 Kuroda, S. 1984. Interaction over food among pygmy chimpanzees. Pp. 301-324 in The pygmy

710 chimpanzee (R. L. Susman, ed.). Springer. New York: Plenum.

711

712 Ladds, Z., Hoppitt, W. and Boogert, N.J. 2017. Social learning in otters. Royal Society open 713 science. 4: 2-3. 
715 Lanszki, J. and Körmendi, S. 1996. Otter diet in relation to fish availability in a fish pond in

716 Hungary. Acta Theriologica. 41:127-136.

717

718 Liévin-Bazin, A., Pineaux, M., Le Covec, M., Gahr, M., Bovet, D. and von Bayern, A.M. 2019.

719 Food sharing and affiliation: An experimental and longitudinal study in cockatiels (Nymphicus

720 hollandicus). Ethology. 125:276-288.

721 Lombardi, C. 2002. Zoo standards for keeping otters in captivity.

$722<$ https://www.pjc.cc.fl.us/sctag/otterstandards.doc.

723 Macnair, M.R. and Parker, G.A. 1979. Models of parent-offspring conflict. III. Intra-brood

724 conflict. Animal Behaviour. 27:1202-1209.

725

726 Marshall, J.T. 1988. Mammals of Thailand. Pp 296-487 in Association for the Conservation of

727 Wildlife. (Lekagul, B. and McNeely, J. eds.). Thailand.

728

729 Mason, C.F. and Macdonald, S.M. 1987. The use of spraints for surveying otter Lutra lutra

730 populations: an evaluation. Biological conservation. 41:167-177.

731

732 McGrew, W.C. and William, C. 1975. Patterns of plant food sharing by wild chimpanzees.

733 Contemporary primatology. 304-309.

734

735 Mock, D. W. and Parker G A.1997. The Evolution of Sibling Rivalry. Oxford University Press.

736 Oxford. 
738 Mock, D.W., Dugas, M.B. and Strickler, S.A. 2011. Honest begging: expanding from signal of

739 need. Behavioral Ecology. 22:909-917.

741 Morrison, P., Rosenmann, M. and Estes, J.A. 1974. Metabolism and thermoregulation in the sea

742 otter. Physiological zoology. 47:218-229.

743

744 Nishida, T. and Turner, L.A. 1996. Food transfer between mother and infant chimpanzees of the

745 Mahale Mountains National Park, Tanzania. International journal of primatology. 17:947-968.

746

747 Parker, G.A. 1985. Models of parent-offspring conflict. V. Effects of the behaviour of the two

748 parents. Animal Behaviour. 33:519-533.

749

750 Parker, G.A., Royle, N.J. and Hartley, I.R. 2002. Begging scrambles with unequal chicks:

751 interactions between need and competitive ability. Ecology Letters. 5:206-215.

752

753 Porter, R.H., Moore, J.D. and White, D.M. 1981. Food sharing by sibling vs nonsibling spiny

754 mice (Acomys cahirinus). Behavioral Ecology and Sociobiology. 8:207-212.

755

756 Price, K. and Ydenberg, R. 1995. Begging and provisioning in broods of asynchronously-

757 hatched yellow-headed blackbird nestlings. Behavioral Ecology and Sociobiology. 37:201-208. 758 
759 Quillfeldt, P. and Masello, J.F. 2004. Context-dependent honest begging in Cory's shearwaters

760 (Calonectris diomedea): influence of food availability. Acta ethologica. 7:73-80.

761

762 Rapaport, L.G. and Ruiz-Miranda, C.R. 2002. Tutoring in wild golden lion

763 tamarins. International Journal of Primatology. 23:1063-1070.

764

765 R Development Core Team. (2019. R: A language and environment for statistical computing. R

766 Foundation for Statistical Computing. Vienna, Austria. https://www.R-project.org/.

767

768 Rose, L.M. 1997. Vertebrate predation and food-sharing in Cebus and Pan. International Journal 769 of Primatology. 18: 727-765.

770

771 Royle, N.J., Hartley, I.R. and Parker, G.A. 2002. Begging for control: when are offspring

772 solicitation behaviours honest?. Trends in Ecology \& Evolution. 17:434-440.

773

774 Ruiz-Miranda, C.R., Kleiman, D.G., Dietz, J.M., Moraes, E., Grativol, A.D., Baker, A.J. and

775 Beck, B.B. 1999. Food transfers in wild and reintroduced golden lion tamarins, Leontopithecus

776 rosalia. American Journal of Primatology: Official Journal of the American Society of

777 Primatologists. 48:305-320.

778

779 Smith, H.G. and Montgomerie, R. 1991. Nestling American robins compete with siblings by

780 begging. Behavioral Ecology and Sociobiology. 29:307-312. 
782 Stacey, P.B. and Koenig, W.D. (eds.) 1990. Pp 215-462 in Cooperative breeding in birds: long

783 term studies of ecology and behaviour. Cambridge University Press. Cambridge, Great Britain.

784

785 Stalmaster, M.V. and Gessaman, J.A. 1984. Ecological energetics and foraging behaviour of 786 overwintering bald eagles. Ecological Monographs. 54:407-428.

787

788 Stamps, J.A., Metcalf, R.A. and Krishnan, V.V. 1978. A genetic analysis of parent-offspring 789 conflict. Behavioral Ecology and Sociobiology. 3:369-392.

790

791

792

Silk, J.B. 1978. Patterns of food sharing among mother and infant chimpanzees at Gombe

793

National Park, Tanzania. Folia primatological. 29:129-141.

794

795 Silk, J.B., Brosnan, S.F., Henrich, J., Lambeth, S.P. and Shapiro, S. 2013. Chimpanzees share

796 food for many reasons: the role of kinship, reciprocity, social bonds and harassment on food 797 transfers. Animal behaviour. 85:941-947.

798

799

Sivasothi, N. and Nor, B.H.M. 1994. A review of otters (Carnivora: Mustelidae: Lutrinae) in

800 Malaysia and Singapore. In Ecology and Conservation of Southeast Asian Marine and

801 Freshwater Environments including Wetlands. 285:151-170.

802

803 Spelman, L.H. 1999. Otter anesthesia. Zoo and Wild Animal Medicine: Current Therapy, 4:436804443.

805 
806 Stevens, J.R. 2004. The selfish nature of generosity: harassment and food sharing in

807 primates. Proceedings of the Royal Society of London. Series B: Biological Sciences. 271:451808456.

809

810 Stevens, J.R. and Gilby, I.C. 2004. A conceptual framework for nonkin food sharing: timing and

811 currency of benefits. Animal Behaviour. 67:603-614.

812

813 Stevens, J.R. and Stephens, D.W. 2002. Food sharing: a model of manipulation by

814 harassment. Behavioral Ecology. 13:393-400.

815

816 Thiollay, J.M. 1991. Foraging, home range use and social behaviour of a group-living rainforest 817 raptor, the Red-throated Caracara Daptrius americanus. Ibis. 133:382-393.

818

819 Thometz, N.M., Tinker, M.T., Staedler, M.M., Mayer, K.A. and Williams, T.M. 2014. Energetic 820 demands of immature sea otters from birth to weaning: implications for maternal costs, 821 reproductive 36ehaviour and population-level trends. Journal of Experimental Biology. $822 \quad 217: 2053-2061$.

823

824 Timm-Davis, L.L., DeWitt, T.J. and Marshall, C.D. 2015. Divergent skull morphology supports 825 two trophic specializations in otters (Lutrinae). PloS one. 10:2-3. 826

827 Trivers, R.L. 1971.The evolution of reciprocal altruism. The Quarterly review of biology. 46:3582857. 
830 Trivers, R.L., 1974. Parent-offspring conflict. Integrative and Comparative Biology. 14:249-264.

831

832 Tukey, J.W. 1977. Exploratory data analysis. Addison-Wesley, Massachusetts, United States.

$8332: 1-20$.

834

835 Ueno, A. and Matsuzawa, T. 2004. Food transfer between chimpanzee mothers and their

836 infants. Primates. 45:231-239.

837

838 Vahed, K. 1998. The function of nuptial feeding in insects: a review of empirical

839 studies. Biological Reviews. 73:43-78.

840

841 von Bayern, A.M., de Kort, S.R., Clayton, N.S. and Emery, N.J. 2007. The role of food-and

842 object-sharing in the development of social bonds in juvenile jackdaws (Corvus

843 monedula). Behaviour. 144:711-733.

844

845 Watt, J. 1991. Prey selection by coastal otters (Lutra lutra). PhD dissertation, University of

846 Aberdeen. Scotland, Great Britain.

847

848 Watt, J. 1993. Ontogeny of hunting behaviour of otters (Lutra lutra L.) in a marine environment.

849 In Symposia of the Zoological Society of London. 65:87-104.

850 
851 Watson, K.A. and Ritchison, G. 2018. Effect of variation in nestling hunger levels on the

852 begging behaviour of nestlings and the provisioning behaviour of adult American Kestrels.

853 Avian Biology Research. 11:35-43.

854

855 Wayre, P. 1978. Status of otters in Malaysia, Sri Lanka and Italy. In Otters (N. Duplaix, ed).

856 Proceedings of the First Working Meeting of the Otter Specialist Group, International Union for

857 the Conservation of Nature, Gland, Switzerland.152-155.

858 Wilkinson, G.S. 1984. Reciprocal food sharing in the vampire bat. Nature. 308:181-184.

859

860 Wilkinson, G.S., Carter, G.G., Bohn, K.M. and Adams, D.M. 2016. Non-kin cooperation in

861 bats. Philosophical Transactions of the Royal Society B: Biological Sciences. 371:1-6.

862

863 Woo, K.J., Elliott, K.H., Davidson, M., Gaston, A.J. and Davoren, G.K. 2008. Individual

864 specialization in diet by a generalist marine predator reflects specialization in foraging

865 behaviour. Journal of Animal Ecology. 77:1082-1091.

866

867 Wrangham, R.W. 1975. Behavioural ecology of chimpanzees in Gombe National Park,

868 Tanzania. PhD dissertation, University of Cambridge. Cambridge, United Kingdom

869

870 Wright, J. and Leonard, M.L. 2007. Pp. 343-337 in The evolution of begging: competition,

871 cooperation and communication (eds.) Kluwer Academic Publishers. Dordrecht, The

872 Netherlands.

873 
874 Wright, B.M., Stredulinsky, E.H., Ellis, G.M. and Ford, J.K. 2016. Kin-directed food sharing 875 promotes lifetime natal philopatry of both sexes in a population of fish-eating killer whales, 876 Orcinus orca. Animal Behaviour. 115:81-95.

877

878 Zahavi, A. 1975. Mate selection — a selection for a handicap. Journal of theoretical Biology. $879 \quad 53: 205-214$.

880

881

882

883

884 


\section{Table 1 (on next page)}

Generalised linear mixed effects model showing how the amount of begging an otter received influenced how often they shared food.

Intercept refers to total "sharing" when begging received is 0 . The significant values are highlighted in bold. 


\begin{tabular}{|c|c|c|c|c|c|c|}
\hline \multicolumn{7}{|c|}{ GLMM output } \\
\hline \multicolumn{2}{|c|}{ Begging and food transfers } & $B$ & $S E$ & $d f$ & $z$ & $p$ \\
\hline \multicolumn{2}{|c|}{ Fixed effects } & & & & & \\
\hline (Intercept) & & -2.655 & 0.146 & & -18.226 & $<.001$ \\
\hline \multicolumn{2}{|c|}{ Begging received } & 0.091 & 0.025 & 1 & 3.562 & $<.001$ \\
\hline \multicolumn{2}{|c|}{ Random effects } & Variance & & & & \\
\hline$o b s$ & (intercept) & 0.233 & & & & \\
\hline$I D$ & (intercept) & 0.067 & & & & \\
\hline trial & (intercept) & 0.144 & & & & \\
\hline & & & & & & \\
\hline Observation & 180 & & & & & \\
\hline$I D$ & 20 & & & & & \\
\hline
\end{tabular}




\section{Table 2 (on next page)}

Generalised linear mixed effects model results showing how food type, food abundance, age category, sex and zoo correlated with the total amount of begging shown by otters.

Intercept refers to "crab" food type, "low" food abundance, "adult" age category, "female" sex and "Newquay" zoo. The significant values are highlighted in bold. 


\begin{tabular}{|c|c|c|c|c|c|c|}
\hline \multicolumn{2}{|c|}{ GLMM output } & \multirow[b]{2}{*}{$B$} & \multirow[b]{2}{*}{$S E$} & \multirow[b]{2}{*}{$d f$} & \multirow[b]{2}{*}{$z$} & \multirow[b]{2}{*}{$p$} \\
\hline Begging & & & & & & \\
\hline \multicolumn{7}{|l|}{ Fixed effects } \\
\hline (Intercept) & & -2.935 & 0.395 & & -7.429 & $<.001$ \\
\hline \multirow[t]{3}{*}{ Food type } & crab & 0 & 0 & & & \\
\hline & mussel & -0.625 & 0.335 & 2 & -1.869 & 0.062 \\
\hline & trout & -0.490 & 0.339 & 2 & -1.444 & 0.149 \\
\hline \multirow[t]{3}{*}{ Food density } & low & 0 & 0 & & & \\
\hline & medium & -0.078 & 0.331 & 2 & -0.236 & 0.813 \\
\hline & high & -0.673 & 0.343 & 2 & -1.966 & 0.049 \\
\hline \multirow[t]{2}{*}{ Age category } & adult & 0 & 0 & & & \\
\hline & juvenile & 0.655 & 0.218 & 1 & 3.004 & 0.003 \\
\hline \multirow[t]{2}{*}{ Sex } & female & 0 & & & & \\
\hline & male & 0.043 & 0.215 & 1 & 0.201 & 0.840 \\
\hline \multirow[t]{2}{*}{ Zoo } & Newquay & 0 & 0 & & & \\
\hline & Tamar & 0.529 & 0.310 & 1 & 1.706 & 0.088 \\
\hline \multicolumn{2}{|c|}{ Random effects } & Variance & & & & \\
\hline$o b s$ & (Intercept) & 0.433 & & & & \\
\hline$I D$ & (Intercept) & 0.081 & & & & \\
\hline trial & (Intercept) & 0.198 & & & & \\
\hline Observation & 180 & & & & & \\
\hline$I D$ & 20 & & & & & \\
\hline
\end{tabular}




\section{Table 3 (on next page)}

Generalised linear mixed effects model showing how food type, food abundance, age category, sex and zoo correlated with the total amount of voluntary food sharing by otters.

Intercept refers to "crab" food type, "low" food abundance, "adult" age category, "female" sex and "Newquay" zoo. The significant values are highlighted in bold. 


\begin{tabular}{|c|c|c|c|c|c|c|}
\hline \multicolumn{2}{|c|}{ GLMM output } & \multirow[b]{2}{*}{$B$} & \multirow[b]{2}{*}{$S E$} & \multirow[b]{2}{*}{$d f$} & \multirow[b]{2}{*}{$z$} & \multirow[b]{2}{*}{$p$} \\
\hline Sharing & & & & & & \\
\hline \multicolumn{7}{|l|}{ Fixed effects } \\
\hline (Intercept) & & -2.477 & 0.355 & & -6.983 & $<.001$ \\
\hline \multirow[t]{3}{*}{ Food type } & crab & 0 & 0 & & & \\
\hline & mussel & -0.195 & 0.280 & 2 & -0.697 & 0.486 \\
\hline & trout & 0.060 & 0.292 & 2 & 0.207 & 0.836 \\
\hline \multirow[t]{3}{*}{ Food density } & low & 0 & 0 & & & \\
\hline & medium & 0.395 & 0.289 & 2 & 1.365 & 0.172 \\
\hline & high & 0.253 & 0.290 & 2 & 0.872 & 0.383 \\
\hline \multirow[t]{2}{*}{ Age category } & adult & 0 & 0 & & & \\
\hline & juvenile & -0.844 & 0.206 & 1 & -4.105 & $<.001$ \\
\hline \multirow[t]{2}{*}{ Sex } & female & 0 & & & & \\
\hline & male & -0.155 & 0.208 & 1 & -0.742 & 0.458 \\
\hline \multirow[t]{2}{*}{ Zoo } & Newquay & 0 & 0 & & & \\
\hline & Tamar & -0.173 & 0.276 & 1 & -0.625 & 0.532 \\
\hline \multicolumn{2}{|c|}{ Random effects } & Variance & & & & \\
\hline$o b s$ & (Intercept) & 0.157 & & & & \\
\hline$I D$ & (Intercept) & 0.084 & & & & \\
\hline trial & (Intercept) & 0.127 & & & & \\
\hline Observation & 180 & & & & & \\
\hline$I D$ & 20 & & & & & \\
\hline
\end{tabular}




\section{Table 4 (on next page)}

Generalised linear mixed effects model showing how the age composition of otter dyads correlated with the total amount of voluntary food sharing between them.

Intercept refers to "adult-adult" sharing. The first individual indicates the food sharer while the second indicates the receiver. Significant values are highlighted in bold. 


\begin{tabular}{|c|c|c|c|c|c|c|}
\hline GLMM output & & & & & & \\
\hline directional sharing & & $B$ & $S E$ & $d f$ & $z$ & $p$ \\
\hline \multicolumn{7}{|l|}{ Fixed effects } \\
\hline (Intercept) & & -4.505 & 0.2109 & & -21.357 & $<.001$ \\
\hline \multirow[t]{4}{*}{ Age category } & AA & 0 & 0 & & & \\
\hline & AJ & -0.393 & 0.216 & 3 & -1.821 & 0.069 \\
\hline & JA & -1.037 & 0.272 & 3 & -3.811 & $<.001$ \\
\hline & JJ & -0.794 & 0.295 & 3 & -2.694 & 0.007 \\
\hline Random effects & & Variance & & & & \\
\hline$o b s$ & (Intercept) & 0.142 & & & & \\
\hline Breceive & (Intercept) & 0.092 & & & & \\
\hline Ashare & (Intercept) & 0.172 & & & & \\
\hline Observation & 188 & & & & & \\
\hline$I D$ & 20 & & & & & \\
\hline
\end{tabular}


Figure 1

Number of individual food transfers across all trials, as a function of begging received.

The more begging individuals received, the more often they transferred food. Points indicate individual otters. Jitter has been applied to data points to visualise those lying on top of each other.

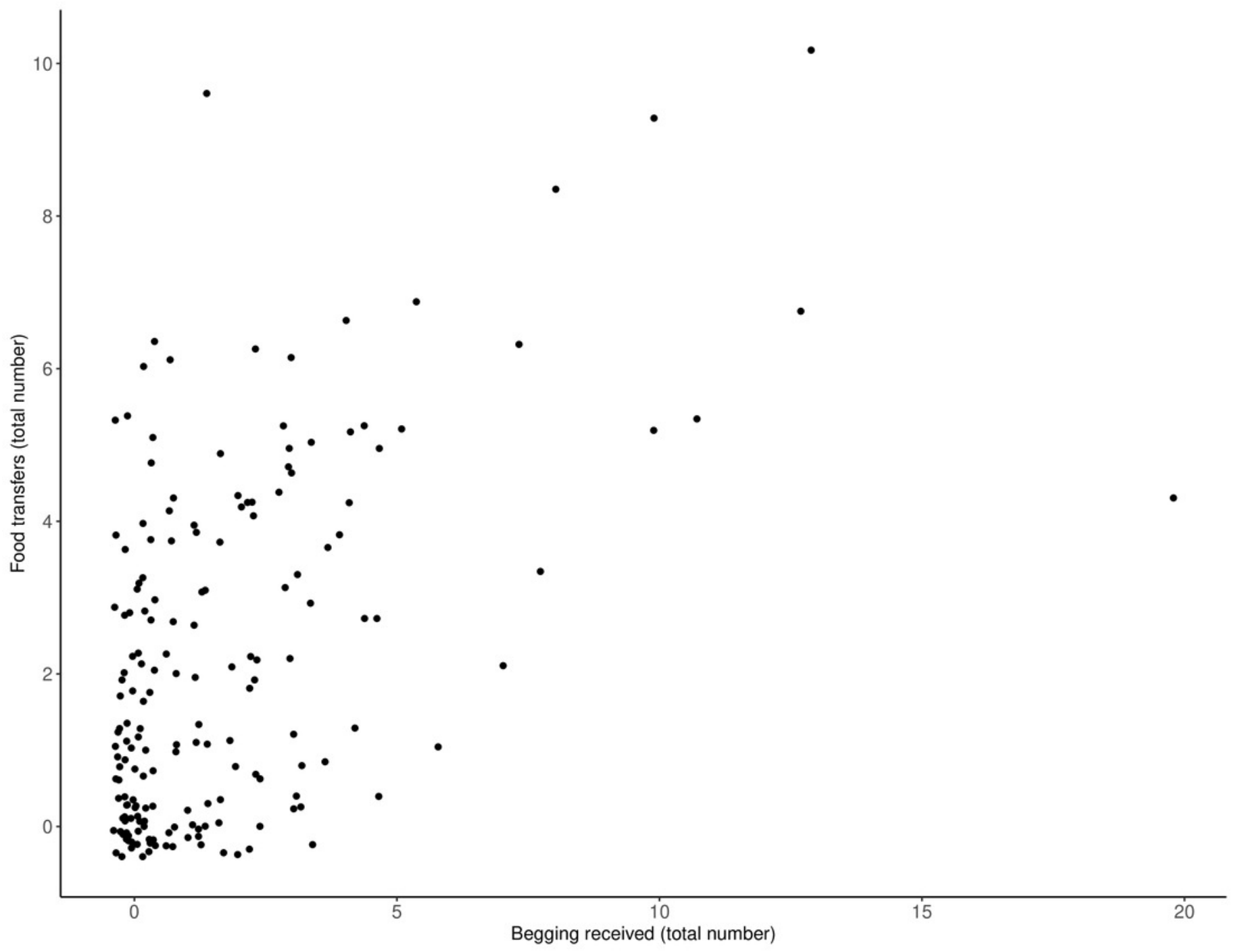




\section{Figure 2}

Individual begging occurrences across all trials, as a function of food abundance and type.

Begging increased when less food was available, but not significantly so. Boxes represent the interquartile range and the bars within the boxes are the median values. Whiskers indicate values within $+/-1.5$ times the interquartile range.

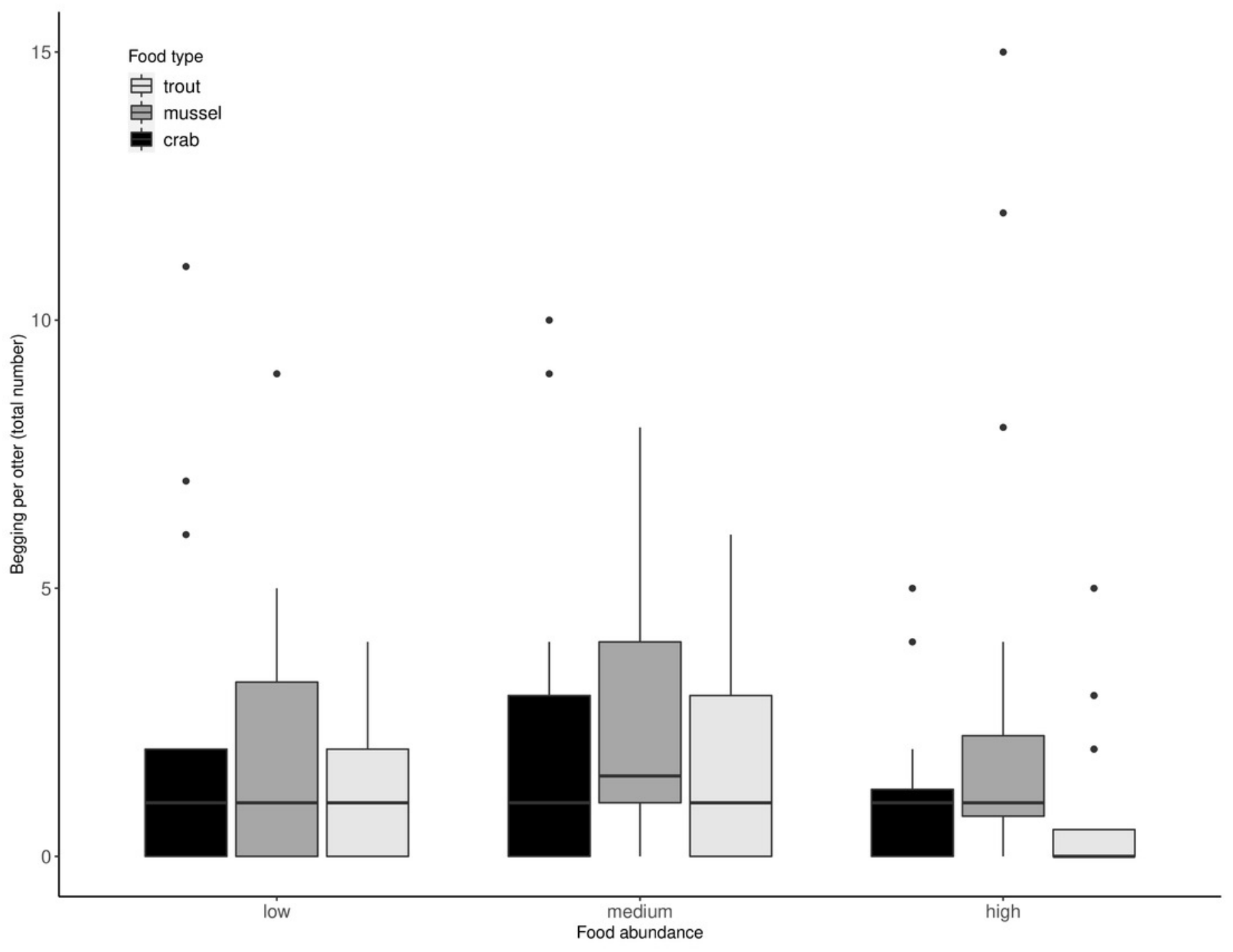


Figure 3

Individual begging occurrences across all trials, as a function of age category.

Juveniles begged more than adults. Boxes represent the interquartile range and the bars within the boxes are the median values. Whiskers indicate values within +/- 1.5 times the interquartile range.

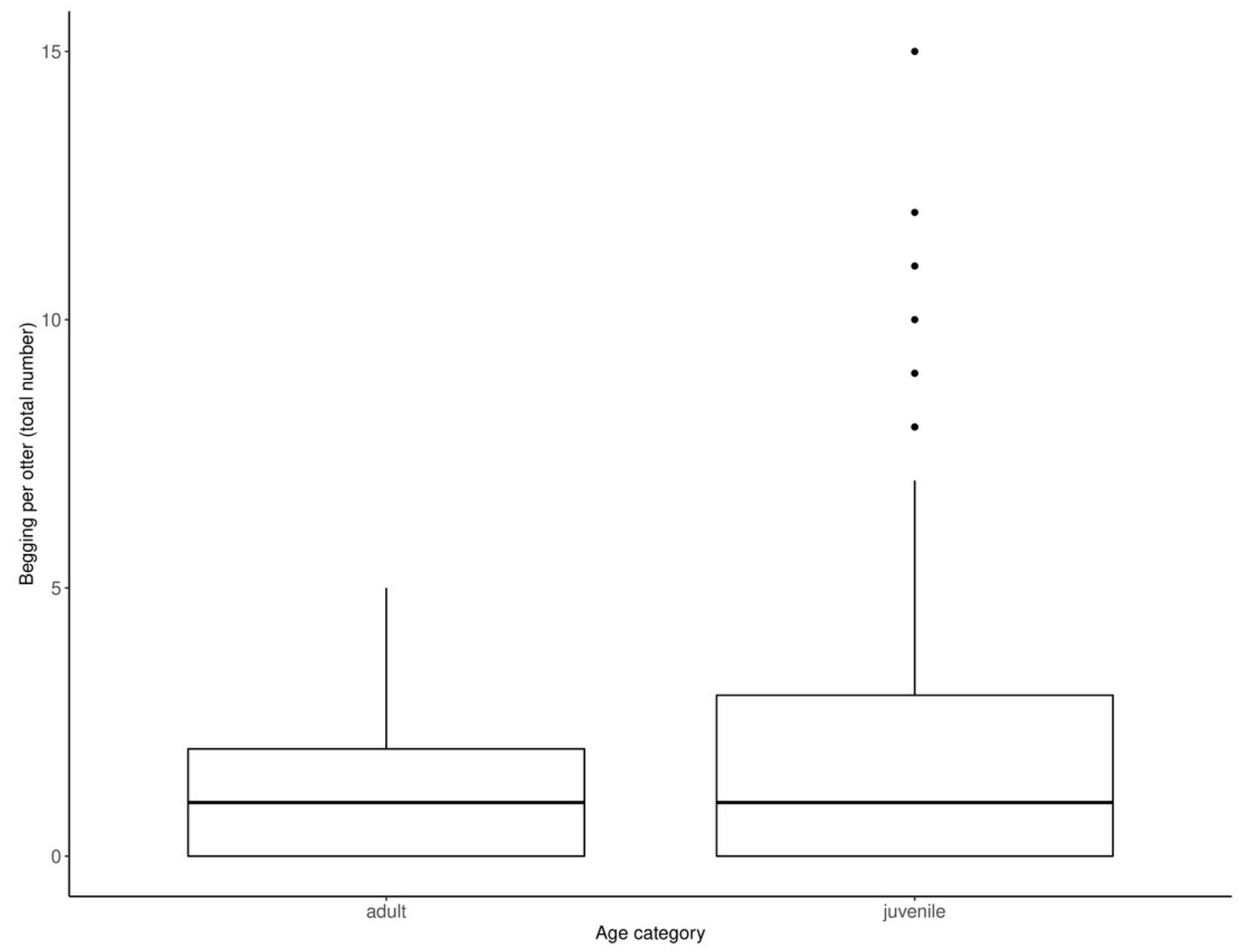


Figure 4

Individual sharing occurrences across all trials, as a function of age category.

Adults shared more often than did juveniles. Boxes represent the interquartile range and the bars within the boxes are the median values. Whiskers indicate values within $+/-1.5$ times the interquartile range.

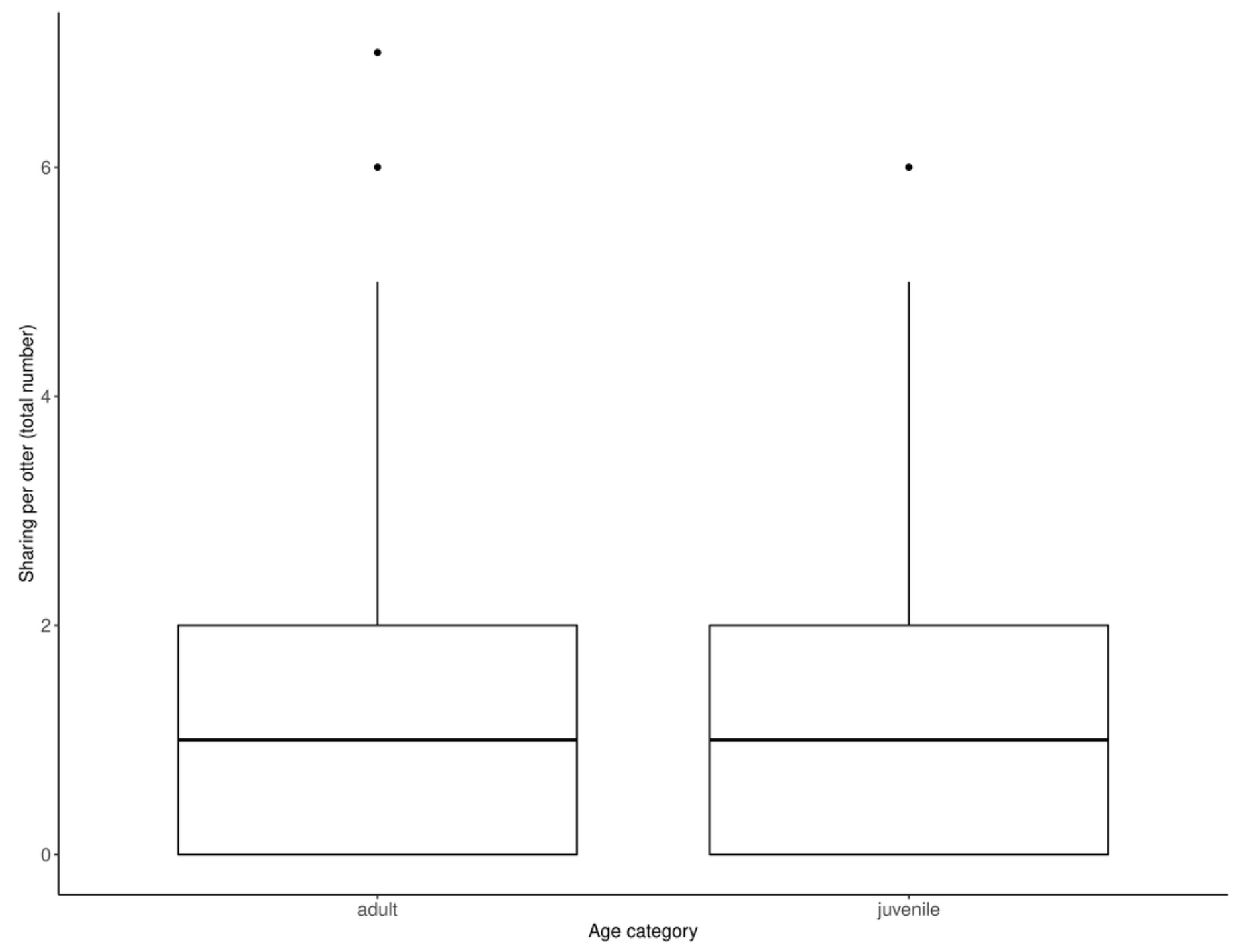




\section{Figure 5}

Dyadic voluntary sharing occurrences across all experimental food presentations as a function of the otter dyad's age composition. The first individual indicates the food sharer while the second indicates the receiver.

Sharing was most frequent amongst adult dyads. Boxes represent the interquartile range and the bars within the boxes are the median values. Whiskers indicate values within +/- 1.5 times the interquartile range.

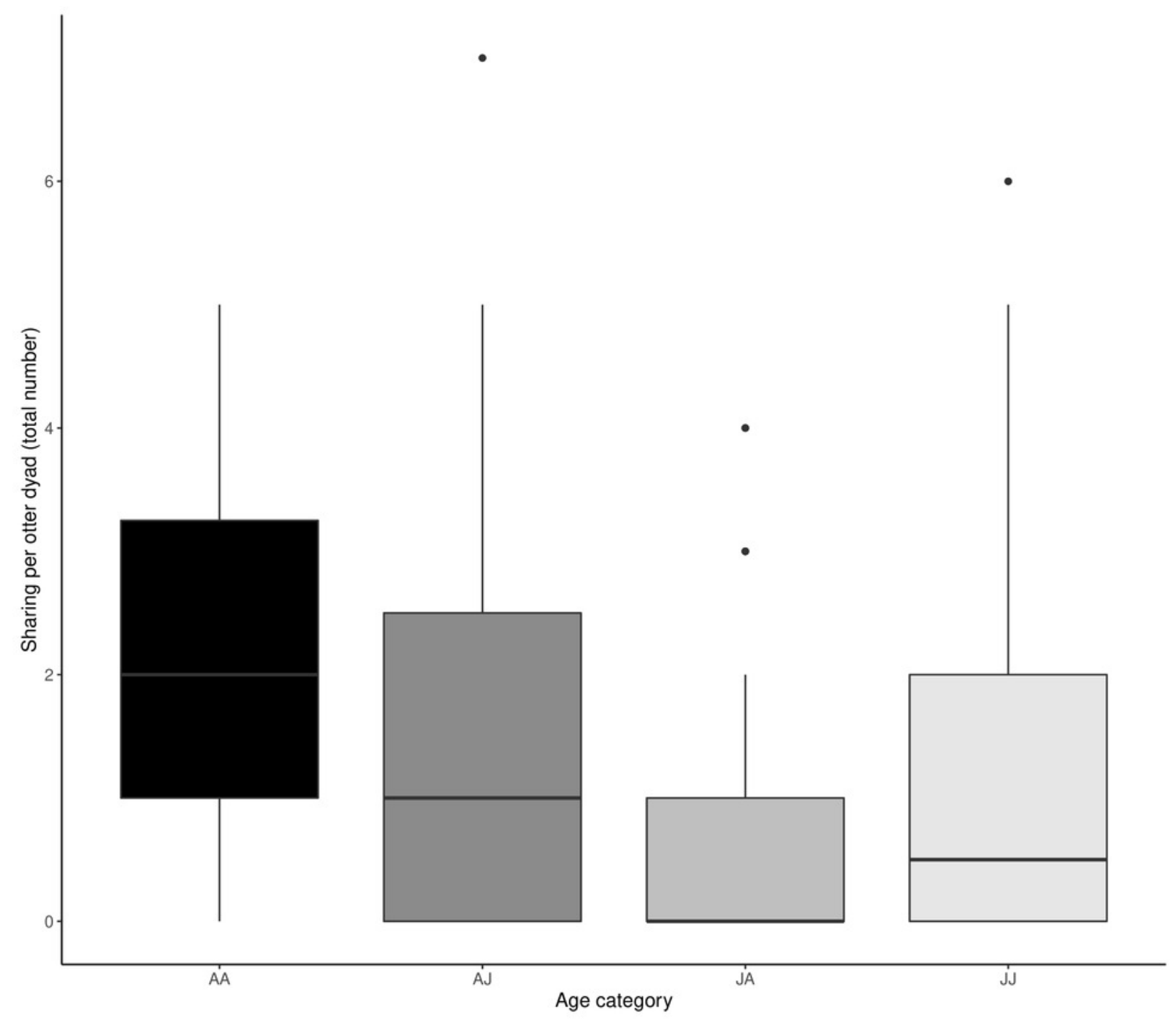

